\title{
Causes Analysis on the Pollution of the South Lake in Wuhan City Based on Fault Tree Theory
}

\author{
Chaoyang Liu ${ }^{1}$, Jingdong Zhang ${ }^{1, \star}$, Fei Li ${ }^{1}$, Bing Wang ${ }^{1}$ and Zhenzhen Qiu $^{1}$ \\ ${ }^{1}$ School of Information and Safety Engineering, Zhongnan University of Economics and Law, Wuhan 430073, China
}

\begin{abstract}
South Lake, the second largest lake in Wuhan, has been polluted seriously in recent years. Unfortunately, specific reasons for the pollution phenomenon impose an insurmountable hurdle. To address this challenge, we used the fault tree theory as a effective tool to conduct comprehensive analysis of the pollution top events. Innovatively, on the basis of integrated area pollution status research, we initiated the qualitative and quantitative analyses of pollution reasons in South Lake. The results showed that there were three main causes leading to the water pollution in South Lake: the weakness of environmental awareness, the lack of government supervision, the frequent of sewage discharge. Notably, we suggested the optimal strategy to make efficient pollution management based on the priority of criticality, which including improving the environmental awareness of businesses and residents, enhancing the government supervision and reducing the discharge frequency. We summarized scientific and objective measures to control water pollution of the South Lake, and it provide a scientific and efficient method to prevent the deterioration of the urban lakes.
\end{abstract}

\section{Introduction}

The South Lake is located in the southwest of Wuchang district in Wuhan, Hubei. It's the second largest lake in Wuhan whose area of water up to 763.96 hectares $^{[1]}$. The South Lake owned vast waters and connected with the Yangtze River in the ancient time, but it has been reduced gradually because of the channel sedimentation and reclaiming farmland from lakes in the recent years. With the development of the city construction and the weakness of the environmental awareness, the South Lake has presented a status of serious eutrophication, which has the tendency to be worse. Due to the South Lake's central location and dense surrounding population, more than half a million people's work and life are influenced directly ${ }^{[2]}$. The pollution of the South Lake is caused by several reasons, and we want to investigate the various causes and factors connected with the water pollution. Our final purpose is to summarize the experience and lessons from the event in order to take measures to prevent the worsening pollution and improve the pollution situation effectively and economically.

The fault tree analysis method in the fault theory is also called the breakdown tree analysis method or the failure tree analysis method. It's the most effective method to analyze the causes of the top events ${ }^{[3]}$. Fault tree analysis is a method which uses the fault tree as a tool to analyze the top event qualitatively and quantitatively $^{[4]}$. Therefore, it's scientific and reasonable to use the fault tree analysis method to analyze the reasons of water pollution in the South Lake, with which we can find the main causes of the pollution to evaluate the risk and achieve the purpose of designing suitable prevention schemes and measures.

\section{The pollution and governance status of the South Lake}

At present, there are 25 drain outlets around the South Lake, and the total wastewater discharge is up to 145 thousand tons ${ }^{[5]}$. Luoshi South Road outlet, Airport second road extension outlet, Mingdu Garden outlet, Chashanliu outlet and South-central university for nationalities outlet are account for $80 \%$ of the total sewage in the South Lake ${ }^{[6]}$. In addition, the South Lake is in peak season of reclaiming farmland from lakes in recent five years. There are dozens of commercial residential buildings around the South Lake, and they discharge more than 40 million tons sewage into the lake, which makes them become the biggest pollution source of the South Lake ${ }^{[7]}$. The detection results made by Hongshan District and East Lake High-tech Development Zone in May 2015 are as follow: ammonia nitrogen (7.02), total phosphorus (8.38), COD (0.13), water quality is in class V. Ammonia nitrogen and total phosphorus are exceeding classifying in class IV, and the water presents the status of serious eutrophication. As for the total phosphorus, we present the change line of the total phosphorus in the South Lake from September 2012 to July 2013(Figure 1).

Pollution prevention in the South Lake has been a piece of "heart disease" of the provincial and municipal governments. In the past five years, Wuhan municipal government has invested billions to control the pollution of the South Lake, and they made great efforts to intercept sewage outlet, dispose facility constructions dispersedly, transform the residential facilities of nitrogen

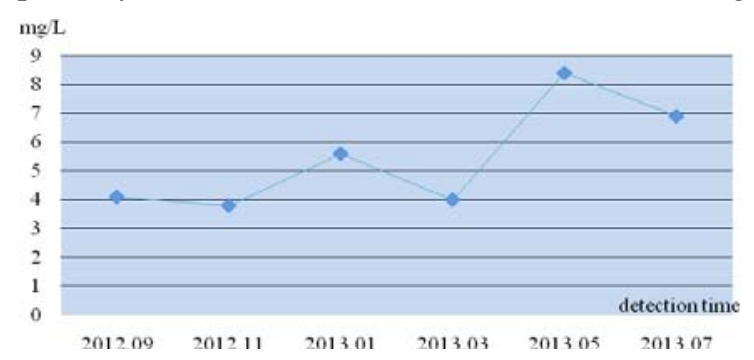

Figure 1. The change line of the total phosphorus in The South Lake from September 2012 to July 2013.

and phosphorus removal, build and improve sewage treatment plants and collection system, perfect related 
projects, construct green belts of the lake, and so on ${ }^{[8]}$. However, due to serious pollution history, the present situation is still severe, and the reduction and prevention measures are difficult. As far as the present situation, the effect of government pollution regulation is not obvious, and the environmental of the South Lake recovers slowly ${ }^{[9]}$.

Therefore, it's urgent to find out the pollution causes in The South Lake, and to seek for the best governance measures to make it more suitable for human work and life.

\section{The establishment of the fault tree for pollution causes in the South Lake}

Taking the water pollution in the South Lake as the top event of the fault tree, we can get the fault tree graph by investigating the pollution causes of the South Lake (Figure 2)

In Figure 2: $\mathrm{X}_{1}$-The backward of production technologies in enterprises; $\mathrm{X}_{2}$-The high cost for enterprises to reduce pollutant concentration ; $\mathrm{X}_{3}$-The weak of environmental awareness ; $\mathrm{X}_{4}$-The lack of government supervision ; $\mathrm{X}_{5}$-The behindhand of sewage treatment technologies ; $\mathrm{X}_{6}$-The lack of investment in sewage treatment; $\mathrm{X}_{7}$-The unreasonable planning of the urban sewage treatment facilities; $\mathrm{X}_{8}$-The incomplete of sewage discharging system; $\mathrm{X}_{9}$-The incomplete of trash treatment facilities ; $\mathrm{X}_{10}$-The lack of investment in trash treatment; $\mathrm{X}_{11}$-The behindhand of trash treatment technologies; $\mathrm{X}_{12}$-The unreasonable for site planning; $\mathrm{X}_{13}$-The shortage of fund; $\mathrm{X}_{14}$-The low quality of the cultivation staffs; $\mathrm{X}_{15}$-The defective of ecological cultivation technologies; $\mathrm{X}_{16}$-Too many pollutant sources; $\mathrm{X}_{17}$-The frequent of sewage discharging; $\mathrm{X}_{18}$-The reducing of lake for filling the lake as land; $\mathrm{X}_{19}$-The lack of clear the sludge in time; $\mathrm{X}_{20}$-The invasion of alien species; $\mathrm{X}_{21}$-The serious of precious pollution.

In order to understand the impact of the 21 basic events (the South Lake pollution factors) on the water pollution in the South Lake, we collected data by questionnaire survey. In the questionnaire design, we divided the impact of the basic events $\left(\mathrm{X}_{\mathrm{i}}, \mathrm{i}=1,2, \ldots, 21\right)$ into three classes: A (quite important), B (relatively important), C (moderate secondary). The respondents were composed of a expert group with 21 water conservation professors from 8 colleges including Huazhong Agricultural University, South-central university for nationalities, Wuhan University of Technology, Hubei University of Technology, and a resident group with random sampling residents living around the South Lake. In the survey, the expert group were issued 20 questionnaires, and we recovered 20 valid questionnaires (100\%). The resident group were issued 133 questionnaires, and we recovered 130 valid questionnaires(97.7\%). In the quantitative analysis of each basic event $\left(X_{i}, i=1,2, \ldots, 21\right)$, the basic events of the $\mathrm{A}, \mathrm{B}, \mathrm{C}$ levels were assigned to $0.5,0.3,0.2$ points. We synthesized the factors such as the knowledge structure, specialty of the expert group and the resident group. We calculated the specific weight of each basic event according to the following formula:

$$
P_{j}\left(X_{i}, i=1,2 \ldots 21\right)=F_{j}\left(X_{i}, i=1,2 \ldots 21\right) / 21 \times N_{j}
$$

In the formula: $\mathrm{P}_{\mathrm{j}}$-The weight of each basic event; $\mathrm{F}_{\mathrm{j}}$ The total survey score of each basic event; $\mathrm{N}_{\mathrm{j}}$-The number of recovered valid questionnaires; $j=1$ means the expert group; $j=2$ means the resident group.

The total weight of each basic event was calculated according to the following formula:

$$
P=P_{1} \times 70 \%+P_{2} \times 30 \%
$$

The calculation results of the survey are showed as Table 1:

Due to the survey is universal and representative, the calculated proportions of each basic event above are approximatively equivalent to the probabilities of each basic event in this case. In the quantitative analysis of the fault tree method, it's scientific and reasonable for us to use the total gravity of each basic event to predict the risk of the water pollution in the South Lake, which has great reference values.

\section{The analysis of the fault tree for pollution causes in the South Lake}

In this system, there are many OR gates in the fault tree and quite a lot of influence factors in the whole pollution incident, so the number of the minimum cut sets is large, which means there are many changing patterns of the event ${ }^{[10]}$. Therefore, we use the EasyDraw Fault Tree Analysis Software to analyze the causes of the water pollution in the South Lake from two aspects: qualitative analysis and quantitative analysis. 


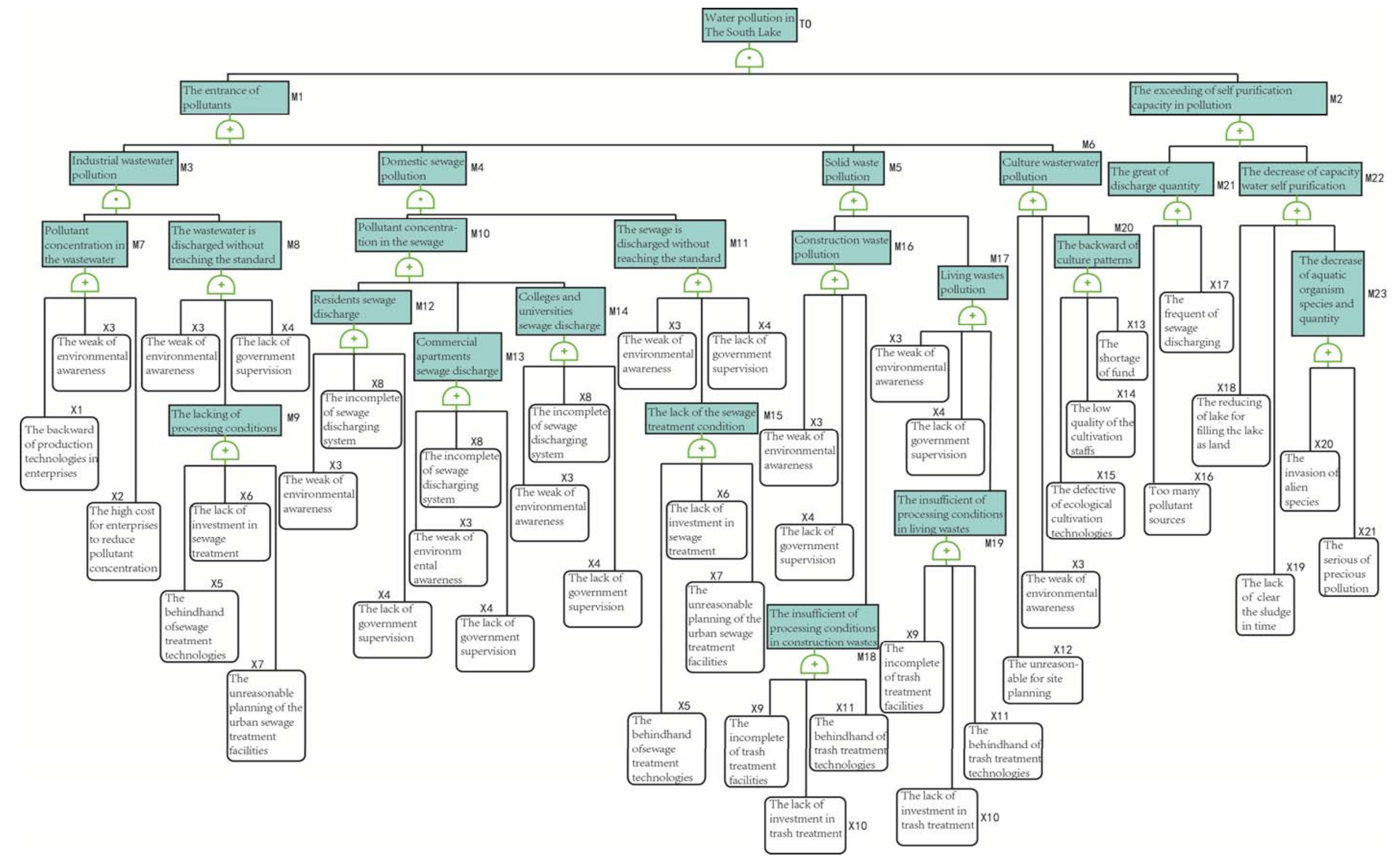

Figure 2. The fault tree graph of the pollution causes in the South Lake 
Table 1. The survey results of the basic events proportion

\begin{tabular}{|c|c|c|c|c|c|c|c|c|c|c|c|c|c|c|c|c|c|c|c|c|c|}
\hline $\begin{array}{c}\text { eve } \\
\text { nt }\end{array}$ & $\begin{array}{c}X \\
1\end{array}$ & $\begin{array}{c}X \\
2\end{array}$ & $\begin{array}{c}X \\
3\end{array}$ & $\begin{array}{c}X \\
4\end{array}$ & $\begin{array}{c}X \\
5\end{array}$ & $\begin{array}{c}X \\
6\end{array}$ & $\begin{array}{c}X \\
7\end{array}$ & $\begin{array}{c}\mathbf{X} \\
\mathbf{8}\end{array}$ & $\begin{array}{c}X \\
9\end{array}$ & $\begin{array}{c}X \\
10\end{array}$ & $\begin{array}{c}X \\
11\end{array}$ & $\begin{array}{c}X \\
12\end{array}$ & $\begin{array}{c}X \\
13\end{array}$ & $\begin{array}{c}X \\
14\end{array}$ & $\begin{array}{c}X \\
15\end{array}$ & $\begin{array}{c}X \\
16\end{array}$ & $\begin{array}{c}X \\
17\end{array}$ & $\begin{array}{c}X \\
18\end{array}$ & $\begin{array}{c}X \\
19\end{array}$ & $\begin{array}{c}X \\
20\end{array}$ & $\begin{array}{c}X \\
21\end{array}$ \\
\hline $\begin{array}{c}\text { P1 } \\
(\%)\end{array}$ & 1.7 & 1.3 & 8.2 & 6.3 & 2.6 & 3.4 & 3.6 & 1.9 & 1.5 & 1.5 & 1.7 & 1.7 & 1.4 & 1.3 & 1.6 & 1.5 & 2.0 & 1.6 & 1.5 & 1.2 & 1.5 \\
\hline $\begin{array}{c}\text { P2 } \\
(\%) \\
\end{array}$ & 2.1 & 1.9 & 8.1 & 5.7 & 3.7 & 3.5 & 3.8 & 2.2 & 1.9 & 1.9 & 1.9 & 1.8 & 1.6 & 1.7 & 1.8 & 2.1 & 2.1 & 1.8 & 1.8 & 1.8 & 1.7 \\
\hline $\begin{array}{c}\mathbf{P} \\
(\%)\end{array}$ & $\begin{array}{c}1.8 \\
2\end{array}$ & $\begin{array}{c}1.3 \\
9\end{array}$ & $\begin{array}{c}8.1 \\
7\end{array}$ & $\begin{array}{c}6.1 \\
2\end{array}$ & $\begin{array}{c}2.9 \\
3\end{array}$ & $\begin{array}{c}3.4 \\
3\end{array}$ & $\begin{array}{c}3.6 \\
6\end{array}$ & $\begin{array}{c}1.9 \\
9\end{array}$ & $\begin{array}{c}1.6 \\
2\end{array}$ & $\begin{array}{c}1.6 \\
2\end{array}$ & $\begin{array}{c}1.7 \\
6\end{array}$ & $\begin{array}{c}1.7 \\
3\end{array}$ & $\begin{array}{c}1.4 \\
6\end{array}$ & $\begin{array}{c}1.4 \\
2\end{array}$ & $\begin{array}{c}1.6 \\
6\end{array}$ & $\begin{array}{c}1.6 \\
8\end{array}$ & $\begin{array}{c}2.0 \\
3\end{array}$ & $\begin{array}{c}1.6 \\
6\end{array}$ & $\begin{array}{c}1.5 \\
9\end{array}$ & $\begin{array}{c}1.3 \\
8\end{array}$ & $\begin{array}{c}1.5 \\
6\end{array}$ \\
\hline
\end{tabular}

\subsection{Qualitative analysis}

\subsubsection{Analysis of minimum cut set}

Using EasyDraw Fault Tree Analysis Software to get the minimum cut sets of the water pollution causes in the South Lake, we found out 25 minimum cut sets: $\left\{X_{4}\right.$, $\left.\mathrm{X}_{17}\right\} ;\left\{\mathrm{X}_{15}, \mathrm{X}_{17}\right\} ;\left\{\mathrm{X}_{4}, \mathrm{X}_{16}\right\} ;\left\{\mathrm{X}_{11}, \mathrm{X}_{17}\right\} ;\left\{\mathrm{X}_{11}, \mathrm{X}_{21}\right\} ;\left\{\mathrm{X}_{12}\right.$, $\left.X_{17}\right\} ;\left\{X_{3}, X_{17}\right\} ;\left\{X_{13}, X_{21}\right\} ;\left\{X_{1}, X_{18}, X_{7}\right\} ;\left\{X_{1}, X_{7}\right\} ;\left\{X_{1}\right.$, $\left.\mathrm{X}_{20}, \mathrm{X}_{4}\right\} ;\left\{\mathrm{X}_{3}, \mathrm{X}_{20}\right\} ;\left\{\mathrm{X}_{3}, \mathrm{X}_{19}\right\} ;\left\{\mathrm{X}_{4}, \mathrm{X}_{19}\right\} ;\left\{\mathrm{X}_{11}, \mathrm{X}_{19}\right\}$; $\left\{\mathrm{X}_{11}, \mathrm{X}_{18}\right\} ;\left\{\mathrm{X}_{12}, \mathrm{X}_{19}\right\} ;\left\{\mathrm{X}_{14}, \mathrm{X}_{19}\right\} ;\left\{\mathrm{X}_{15}, \mathrm{X}_{19}\right\} ;\left\{\mathrm{X}_{13}, \mathrm{X}_{18}\right\}$; $\left\{X_{13}, X_{19}\right\} ;\left\{X_{3}, X_{21}\right\} ;\left\{X_{4}, X_{18}\right\} ;\left\{X_{3}, X_{18}\right\} ;\left\{X_{4}, X_{21}\right\}$. The result means there are 25 patterns which lead to the water pollution in the South Lake, so the risk of the water pollution in the South Lake is pretty great.

\subsubsection{Analysis of minimum radius set}

Using EasyDraw Fault Tree Analysis Software to get the minimum radius sets of the water pollution causes in the South Lake, we found out 3 minimum radius sets: $\left\{X_{16}\right.$, $\left.\mathrm{X}_{20}, \mathrm{X}_{18}, \mathrm{X}_{19}, \mathrm{X}_{17}, \mathrm{X}_{21}\right\}$; $\left\{\mathrm{X}_{1}, \mathrm{X}_{3}, \mathrm{X}_{9}, \mathrm{X}_{13}, \mathrm{X}_{12}, \mathrm{X}_{4}, \mathrm{X}_{14}\right.$, $\left.X_{15}, X_{11}, X_{8}, X_{2}\right\} ;\left\{X_{5}, X_{9}, X_{13}, X_{3}, X_{4}, X_{12}, X_{6}, X_{7}, X_{14}\right.$, $\left.\mathrm{X}_{15}, \mathrm{X}_{10}, \mathrm{X}_{11}\right\}$. It's means that there are 3 optional schemes to prevent the water pollution in The South Lake. The solution is limited for the mass of basic events, so it's quite difficult to prevent the pollution.

\subsubsection{Analysis of structural importance}

Using EasyDraw Fault Tree Analysis Software to analysis the structural importance for each basic event of the water pollution causes in the South Lake, we get the permutation order: I (19) > I (4) > I (3) = I (17) > I (18) > $\mathrm{I}(21)=\mathrm{I}(11)>\mathrm{I}(13)>\mathrm{I}(1)=\mathrm{I}(15)=\mathrm{I}(12)>\mathrm{I}(20)>\mathrm{I}$ (7) $>I$ (16) $=I$ (14). The basic events at the top are $X_{19}$; $\mathrm{X}_{4} ; \mathrm{X}_{3} ; \mathrm{X}_{17} ; \mathrm{X}_{18} ; \mathrm{X}_{21} ; \mathrm{X}_{11}$, which present great impact on the water pollution in the South Lake, so we should strengthen the prevention and control of these causes.

\subsection{Quantitative analysis}

\subsubsection{The probability of the top event}

Using the approximate algorithmin in the EasyDraw Fault Tree Analysis Software (Not require the accuracy) and the data in the table 1 , we can get the result that the probability of the top event is 0.0153 . As an event need to be prevented, the water pollution in the South Lake is easy to take place. Due to the great risk of the event , it should be paid enough attention.

\subsubsection{Probability importance}

Using the approximate algorithm 1 in the EasyDraw Fault Tree Analysis Software (Not require the accuracy) and the data in the table 1 , we get the permutation order of the probability importance of each basic event: Ig (19) > Ig (17) $>\operatorname{Ig}(18)>\operatorname{Ig}(21)>\operatorname{Ig}(4)>\operatorname{Ig}(20)>\operatorname{Ig}(3)>\operatorname{Ig}$ (11) $>\operatorname{Ig}(16)>\operatorname{Ig}(13)>\operatorname{Ig}(15)>\operatorname{Ig}(12)>\operatorname{Ig}(14)>\operatorname{Ig}$ (1) $>\operatorname{Ig}(7)>\operatorname{Ig}(5)>\operatorname{Ig}(8)=\operatorname{Ig}(9)=\operatorname{Ig}(10)=\operatorname{Ig}(6)=$ Ig (2). According to the result above, we can reduce the possibility of water pollution in the South Lake effectively by clearing the sludge in time, reducing the discharge frequency and pollutant sources, improving and controlling the previous pollution, increasing the government supervision, improving the environmental awareness of businesses and residents, increasing the pollution controlling and technology researching investment.

\subsubsection{Criticality importance}

Using the approximate algorithm 1 in the EasyDraw Fault Tree Analysis Software (Not require the accuracy) and the data in the table 1 , we get the permutation order of the criticality importance of each basic event: Cg (3) > Cg (4) $\mathrm{Cg}(17)>\mathrm{Cg}(19)>\mathrm{Cg}(18)>\mathrm{Cg}(21)>\mathrm{Cg}(11)>\mathrm{Cg}$ (20) $>\mathrm{Cg}(16)>\mathrm{Cg}(13)>\mathrm{Cg}(12)>\mathrm{Cg}(15)>\mathrm{Cg}(14)>$ $\mathrm{Cg}(1)>\mathrm{Cg}(7)>\mathrm{Cg}(5)=\mathrm{Cg}(8)=\mathrm{Cg}(9)=\mathrm{Cg}(10)=$ $\mathrm{Cg}(6)=\mathrm{Cg}$ (2). It measures the importance degree of the basic events from two aspects: the sensitivity and the occurrence probability ${ }^{[11]}$. Therefore, we can choose the most effective and economical measures to prevent the water pollution in the South Lake: improving the environmental awareness of businesses and residents, increasing the government supervision, reducing the discharge frequency, clearing the sludge in time, forbidding filling the lake as land, improving and controlling the previous pollution, increasing the technology of trash treatment, etc.

\section{Summary and recommendations}

The water pollution in the South Lake is a vicious incident, which is easy to occur with high risk. Thus preventing and controlling the water pollution in the South Lake is an important and urgent problem. Through the qualitative analysis, we find there are 25 minimum cut sets and 3 minimum radius sets. It shows that there 
are 25 possibilities will cause the water pollution in the South Lake with few prevention approaches. However, we could come to the conclusion from the three minimum radius sets that we just need to take one of the three plans in order to avoid the pollution of the South Lake. Plan $A:\left\{X_{16}, X_{20}, X_{18}, X_{19}, X_{17}, X_{21}\right\}$, it can ensure that the sewage quantity does not exceed the self purification capacity of the South Lake. Plan B: $\left\{X_{1}, X_{3}, X_{9}, X_{13}, X_{12}\right.$, $\left.\mathrm{X}_{4}, \mathrm{X}_{14}, \mathrm{X}_{15}, \mathrm{X}_{11}, \mathrm{X}_{8}, \mathrm{X}_{2}\right\}$ and Plan C: $\left\{\mathrm{X}_{5}, \mathrm{X}_{9}, \mathrm{X}_{13}, \mathrm{X}_{3}\right.$, $\left.\mathrm{X}_{4}, \mathrm{X}_{12}, \mathrm{X}_{6}, \mathrm{X}_{7}, \mathrm{X}_{14}, \mathrm{X}_{15}, \mathrm{X}_{10}, \mathrm{X}_{11}\right\}$, they could prevent the contaminant emission into the South Lake, thus the pollution can be prevented and controlled. Through comparing the comprehensive index such as the number of basic events in each plan, the structure importance, the probability importance, the criticality importance, the difficulty of changing each basic events (operability, economic investment, technical level, etc.), we come to the conclusion that the optimal plan should be Plan B or Plan C.

Through the analysis of structure importance, we find the main causes of the water pollution in The South Lake are as follows: The weak of environmental awareness, the lack of government supervision, the frequent of sewage discharge, the reducing of lake for filling the lake as land, the lack of clearing the sludge in time, etc. We could choose the optimal scheme to prevent the pollution by the analysis of criticality importance ${ }^{[12]}$, which including: improving the environmental awareness of businesses and residents, enhancing the government supervision, reducing the discharge frequency, clearing the sludge in time, forbidding filling the lake as land, improving and controlling the previous pollution, increasing the technology of trash treatment, etc.

In this paper, the causes of the water pollution in The South Lake are analyzed in depth by the fault tree theory which even suitable for research the factors of a normal pollution incident with a vital significant for refining the treatment scheme, and we seek the main courses of the water pollution from two aspects: qualitative analysis and quantitative analysis. In addition, we have made a scientific evaluation and description on the prevention scheme. We measure optimization and the risk of the pollution in the South Lake, which has great reference value for preventing and controlling water pollution of the South Lake in Wuhan and other lakes.

\section{Acknowledgement}

This research is supported by The Graduate Innovative Education Program of Zhongnan University of Economics and Law. (No. 2015RT05)

\section{References}

[1] W. Wu. Hua Zhong Architect. 07:152-154 (2012)

[2] J. Y. Huang, C. C. Song, Y. Y. Song, D. Y. Liu, Z. M. Wan, Y. J. Liao. Environ Sci. 05:1380-1387 (2013)

[3] A. Khaled, A. Sami, A. Jasem. Safe Sci. 79:184-192 (2015)
[4] Q. Bu, Y. Wang, D. Wang. J. Southwest Petrol Inst. 04:141-144 (2007) [5] G.Li. 01:28-29
http://hygl.whjs.gov.cn/content/201104/29/content_211925.htm

[6] F. Zhou, Q. Sha, W. Hao. J. of Lake Sci. 03:401-409 (2014)

[7] F. Li. (2010), http://www.goootech.com/news/detail10174032.html

[8] Y. Li, J. Li. 01:16-17 (2012), https://www.baidu.com/link?url=lFuFYm7kxgJ1KSx twZQ27Uiq5qRQK73WyoLNNWHT55E6VDSKW RRUM2P7j-maJ2S5scUJVbnNt1usKbZkbnoguxg_L_58grgVnfsx0Xigt W\&wd=\&eqid=b71f06ba0004bab1000000055627a5 37

[9] M. Leng, M. Xiao, H. Fang, X. Zhang, H. Liu. J. of Anhui Agr Sci. 04:2485-2486 (2012)

[10]D. Ge, L. Meng, Y. Yang, R. Xing, C. Qiang. Reliab Eng Syst Safe. 142: 289-299 (2015)

[11]R. Nahid, L. M. R.Miri, Jamal. Safe Sci. 78: 49-59 (2015)

[12]B.N.Singh, G. L. Pahuja, R. Singh. Energ Source Part A. 37: 18 (2015) 